\title{
Reflex Control of Ventricular Refractoriness in the Nonischemic Myocardium during Coronary Occlusion
}

\author{
Kaichiro Kamiya, Takeshi Shimizu,* \\ Junji Toyama, and Kazuo Yamada \\ Department of Circulation and Respiration, The Research Institute of \\ Environmental Medicine, Nagoya University, Nagoya, Aichi, 464 Japan \\ *Department of Cardiology, Chukyo Hospital, Nagoya, Aichi, 457 Japan
}

\begin{abstract}
The purpose of the study was to determine whether activation of cardiac receptors and arterial baroreceptors by myocardial ischemia could elicit reflex alteration of the effective refractory period (ERP) of nonischemic ventricular myocardium in cats. Changes in ERP of nonischemic area of the right ventricle and mean arterial pressure (MAP) were measured during transient left anterior descending (LAD) coronary artery occlusion in anesthetized cats. LAD coronary occlusion for $90 \mathrm{sec}$ caused a small but significant shortening of ERP (maximal change $=2.5 \pm 2.3 \mathrm{msec}$ ) associated with a decrease in MAP. Vagotomy significantly augmented the shortening of ERP to $-3.4 \pm 1.6 \mathrm{msec}$ and attenuated the decrease in MAP. After selective cardiac sympathectomy, the reflex response in refractoriness was virtually abolished. In cats with sinoaortic denervation with intact sympathetic nerves, marked attenuation was observed in the reflex change in refractoriness, although the decrease in MAP was significantly greater. These results indicate that: (1) autonomic reflexes activated during acute myocardial ischemia shorten the refractory period of nonischemic ventricular myocardium; (2) the reflex response is predominantly mediated by enhancement of cardiac sympathetic nerve activity resulting from the reduced baroreceptor activity due to concurrent hypotension.
\end{abstract}

Key Words: effective refractory period, coronary occlusion, autonomic reflexes, nonischemic myocardium.

There is ample evidence in the literature that the recovery of myocardial excitability is significantly affected by either sympathetic or parasympathetic interventions (Brooks et al., 1978; Kralios and Millar, 1981; Martins and ZiPes, 1980; NATTEL et al., 1981; SchwARTZ et al., 1977). Only recently, however, have attempts been made to correlate these changes in ventricular refractoriness with

Received for publication April 16, 1983

神谷香一郎, 清水 武, 外山淳治, 山田和生 
autonomic reflexes mechanisms (BLAIr et al., 1980; LATHERs et al., 1978; MARTINS, 1981). In a study on anesthetized cats, BLAIR et al. (1980) demonstrated that the stimulation of the central end of the cut caudocagal nerve produced significant alterations in the left ventricular refractory period. Although the study demonstrated a cardiocardiac reflex which can alter the refractoriness of the heart, it is still unknown whether the activation of ventricular receptors may exert similar reflex influences on ventricular refractoriness. One of the conditions which alter ventricular receptor activity is acute myocardial ischemia (BROWN, 1967; IWAMURA and BishoP, 1980; MALLIANI et al., 1969; THORÉN, 1976; UCHIDA and Murao, 1974; WeAver et al., 1981). Activation of cardiac receptors during myocardial ischemia has been known to significantly alter both sympathetic and parasympathetic influences on the heart (FELDER and THAMES, 1979; GILLIS, 1971). Furthermore, these autonomic influences could be modified by a change in arterial baroreceptor activity resulting from the hypotension which frequently accompanies acute myocardial ischemia (FELDER and THAMES, 1981; MANCIA et al., 1976; SHImizu et al., 1978).

The purpose of this study was: (1) to investigate whether the activation of cardiac receptors during coronary occlusion could elicit reflex alterations in the refractory period in the nonischemic ventricular myocardium of the feline heart, and (2) to determine the relative functional importance of reflex pathways responsible for the observed changes.

\section{METHODS}

Twenty-nine cats weighing 1.8 to $3.6 \mathrm{~kg}$ were anesthetized with intramuscular ketamine hydrochloride $(30-50 \mathrm{mg} / \mathrm{kg}$ ) followed by intravenous alpha chloralose $(50 \mathrm{mg} / \mathrm{kg})$. Additional amounts of chloralose $(10 \mathrm{mg} / \mathrm{kg})$ were given to maintain anesthesia during the experiment. Muscular movements were eliminated with gallamine triethiodide $(2 \mathrm{mg} / \mathrm{kg}$, i.v.). Arterial pressure was recorded by a pressure transducer connected to a catheter passed retrogradely via the femoral artery to the descending aorta. Mean arterial pressure (MAP) was obtained by electrical averaging. Heart rate was monitored by a cardiotachometer triggered by the QRS complexes from a vertical lead body surface electrocardiogram. Body temperature was maintained by means of an electrical heating pad placed under the animal. MAP, heart rate and the electrocardiogram were continuously monitored on a pen recorder (Nihon Kohden RJC 4004).

After a midcervical incision, the trachea was cannulated and artificial respiration with air was begun. Both the cervical vagi and carotid arteries were dissected for later vagotomy and sinoaortic denervation. The thorax was opened through a transverse incision at the fifth intercostal space, and the fourth and fifth ribs were removed bilaterally. A small incision was made over the right atrium for the placement of a pair of pacing electrodes on the right atrium. A second in- 
cision was made in the pericardium to expose the heart in the left anterior descending (LAD) coronary artery region on the left ventricle. The proximal LAD coronary artery was dissected for approximately $2 \mathrm{~mm}$ from the surrounding tissue. Care was taken not to damage the pericoronary nerves coursing along the vessels. A snare was placed around the vessels for subsequent coronary occlusion. A short test occlusion was then performed to delineate the potentially ischemic area.

For the measurement of refractory period in the ventricular myocardium, which is not affected by ischemia during LAD occlusion, two pairs of bipolar electrodes with an interpolar distance of $1 \mathrm{~mm}$ were inserted about $2 \mathrm{~mm}$ apart into the myocardium of the outflow tract of the right ventricle. Each pair was used either for delivering the premature stimulus or recording the ventricular electrogram in response to the local stimulus. The recording electrodes were connected to a Nihon Kohden amplifier AB 620G. The amplified signal then was displayed on a Tektronix dual beam storage oscilloscope and recorded on the pen recorder (Nihon Kohden RJC 4004). The effective refractory period of nonischemic myocardium was determined with an extrastimulus method using a programmable stimulator (Nihon Kohden SEC 2102N). The series of nine basic stimuli (S1) on the right atrium were followed by a premature stimulus (S2) of 2 msec duration and at intensity of 1.5 times the diastolic threshold current on the right ventricle. To eliminate the influences of coronary occlusion on atrioventricular conduction, oscilloscope sweep was triggered by the ventricular electrogram resulting from the paced beat (R1). The S1-S2 interval was, then, shortened stepwise by $1 \mathrm{msec}$ until S2 failed to elicit the ventricular response. ERP was defined as the time interval from the peak of R1 wave to the earliest premature stimulus (S2) which produced a premature ventricular response.

After these surgical procedures, the heart rate and arterial pressure were allowed to stabilize for about $30 \mathrm{~min}$. Then, atrial pacing was commenced at a rate of 200 beats per min. When the intrinsic heart rate exceeded this level, the pacing rate was adjusted to approximately 20 beats per min above the intrinsic rate. Control ERP before coronary occlusion was determined when the ERP value was stable for three consecutive measurements with the accuracy of $1 \mathrm{msec}$. If ERP changed variably, the recording bipolar electrodes were removed and inserted in another site of the right ventricle. Immediately after measurement of control ERP, the LAD coronary artery was occluded for $90 \mathrm{sec}$ and ERP was determined at each 30 -sec interval during the occlusion. About 10 min after release of coronary occlusion, ERP of nonischemic area was reassessed. If ERP after release of coronary occlusion was different from that before coronary occlusion, the data were discarded. Then, the process was repeated to ensure the reproducibility of the ERP change during occlusion.

To evaluate the possible role of the autonomic nerve in mediating the ERP response to the coronary occlusion, three types of selective autonomic denervation

Vol. 33, No. 5, 1983 
were performed. In 8 cats, bilateral cervical vagi were cut. In 7 cats, selective cardiac sympathetic denervation was performed by cutting all the central and peripheral connections of the right and left stellate ganglia as well as communicating rami of T3-T5. In 8 cats, sinoaortic denervation was performed. Carotid sinuses were denervated bilaterally by sectioning all vessels and nerves between the internal and external carotid arteries. The adequacy of the denervation was ascertained by observing the response of arterial pressure and heart rate to bilateral carotid occlusion and release. In these experiments, both aortic depressor nerves were dissected and cut at their junctions with superior laryngeal nerves. After each denervation, the hemodynamic parameters were allowed to stabilize for about $30 \mathrm{~min}$. The results were averaged in each animal and statistical comparisons were made by using the paired $t$-test. All values are expressed as mean \pm standard deviation.

\section{RESULTS}

Changes in nonischemic ventricular muscle ERP during coronary occlusion

Figure 1 shows the mean changes in ERP of the nonischemic area and arterial pressure during coronary occlusion in 23 experiments. LAD occlusion for $90 \mathrm{sec}$ resulted in a progressive decrease in ERP in the nonischemic area. At $30 \mathrm{sec}$ after occlusion, ERP showed a small decrease $(-0.8 \pm 1.4 \mathrm{msec})$, although it was statistically insignificant. At $60 \mathrm{sec}$ after occlusion, however, ERP was significantly decreased by $1.6 \pm 1.6 \mathrm{msec}(p<0.05)$. The degree of the shortening was further increased at $90 \mathrm{sec}(-2.5 \pm 2.3 \mathrm{msec}, p<0.05)$. Coronary occlusion resulted in a small decrease in arterial pressure at each observation point, but only that obtained at $30 \mathrm{sec}$ after occlusion was statistically significant.

\section{Effects of vagotomy on ERP responses to coronary occlusion}

Vagotomy produced a slight, insignificant decrease in ERP and significant
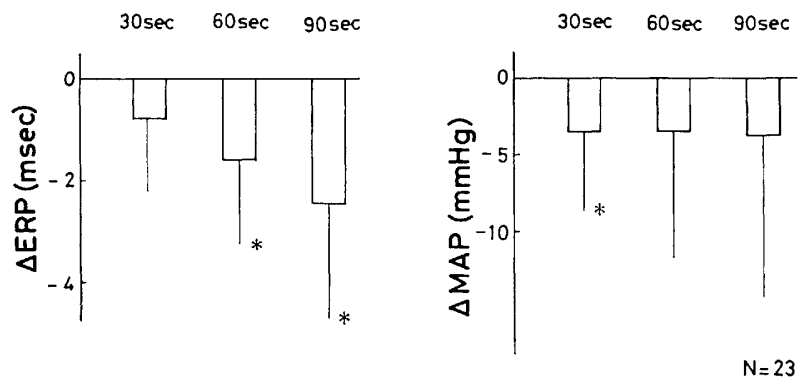

Fig. 1. Time course of changes (mean \pm S.D.) in effective refractory period ( $\Delta \mathrm{ERP}, \mathrm{msec}$ ) of nonischemic area and mean arterial pressure ( $\triangle \mathrm{MAP}, \mathrm{mmHg}$ ) during $90 \mathrm{sec}$ of anterior descending coronary occlusion in cats with neuroaxis intact $(n=21)$. Data are shown for each consecutive 30-sec period of occlusion. * Significantly different from the value before coronary occlusion $(p<0.05)$. 
increases in arterial pressure and heart rate (Table 1). In 8 experiments, ERP changes in the nonischemic area in response to coronary occlusion were determined before and after bilateral vagotomy. Figure 2 illustrates $\triangle E R P$ and $\triangle$ MAP before and after the procedure. Vagotomy significantly augmented the shortening in ERP at three time points after coronary occlusion. As was the case with control occlusion, the degree of shortening after vagotomy was progressively increased with time after coronary occlusion and the maximal decrease in ERP was obtained at $90 \mathrm{sec}(-3.4 \pm 1.6 \mathrm{msec})$. On the other hand, the decrease in arterial pressure during coronary occlusion was significantly attenuated after vagotomy. Thus, at $90 \mathrm{sec}$ after occlusion, $\triangle \mathrm{MAP}$ was only $0.7 \pm 2.6 \mathrm{mmHg}$ after vagotomy which was significantly smaller than that observed with control occlusion $(-8.7 \pm 11.7 \mathrm{mmHg})$.

Table 1. Control ventricular refractoriness, mean arterial pressure and heart rate prior to occlusion before and after selective denervations.

\begin{tabular}{|c|c|c|c|c|c|c|c|}
\hline & \multirow[b]{2}{*}{$n$} & \multicolumn{3}{|c|}{ Control } & \multicolumn{3}{|c|}{ After intervention } \\
\hline & & $\underset{(\mathrm{msec})}{\mathrm{ERP}}$ & $\underset{(\mathrm{mmHg})}{\mathrm{MAP}}$ & $\underset{\text { (beats/min) }}{\mathrm{HR}}$ & $\begin{array}{c}\text { ERP } \\
(\mathrm{msec})\end{array}$ & $\underset{(\mathrm{mmHg})}{\mathrm{MAP}}$ & $\stackrel{\text { HR }}{\text { (beats/min) }}$ \\
\hline \multirow[t]{2}{*}{ Vagotomy } & \multirow[t]{2}{*}{8} & 167.6 & 122.2 & 172.8 & 165.6 & $134.2 *$ & $184.0^{*}$ \\
\hline & & \pm 10.4 & \pm 26.4 & \pm 4.7 & \pm 10.1 & \pm 36.4 & \pm 8.1 \\
\hline \multirow[t]{2}{*}{ Sympathectomy } & \multirow[t]{2}{*}{7} & 165.9 & 113.3 & 175.4 & $171.4^{*}$ & $87.0^{*}$ & 162.6 \\
\hline & & \pm 6.5 & \pm 17.8 & \pm 11.9 & \pm 7.4 & \pm 30.5 & \pm 5.6 \\
\hline \multirow{2}{*}{$\begin{array}{l}\text { Sinoaortic } \\
\text { denervation }\end{array}$} & \multirow[t]{2}{*}{8} & 171.1 & 121.9 & 169.0 & 169.1 & $143.6^{*}$ & 174.0 \\
\hline & & \pm 11.4 & \pm 19.0 & \pm 8.9 & \pm 11.3 & \pm 16.3 & \pm 17.0 \\
\hline
\end{tabular}

ERP, effective refractory period; MAP, mean arterial pressure; HR, heart rate; $n$, number of cats tested. Values are means \pm S.D. * Indicates significant change $(p<$ 0.05 ) when compared to control values.
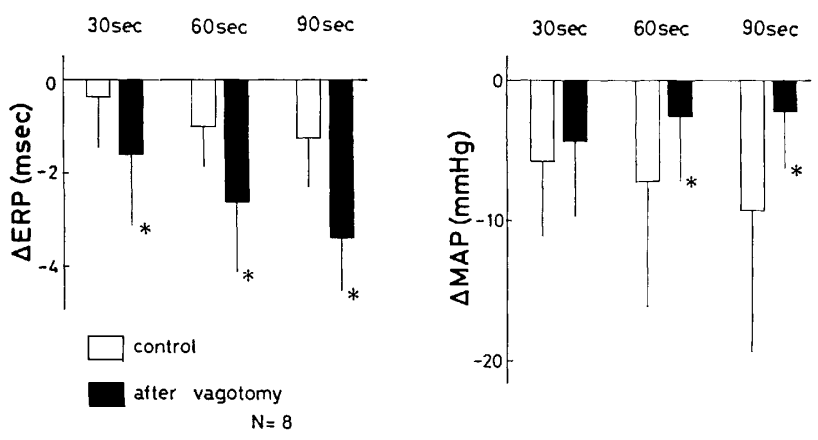

Fig. 2. Time course of changes in effective refractory period ( $\Delta \mathrm{ERP}, \mathrm{msec})$ of nonischemic area and mean arterial pressure $(\triangle \mathrm{MAP}, \mathrm{mmHg})$ during $90 \mathrm{sec}$ of anterior descending coronary occlusion before (open bars) and after (solid bars) bilateral vagotomy in 8 cats. Data are shown for each consecutive 30 -sec period of occlusion. Significant differences $(p<0.05)$ between means for pre- $v s$. post-vagotomy $(*)$ are so indicated. 


\section{Effects of cardiac sympathectomy on ERP responses to coronary occlusion}

In all 7 experiments, selective cardiac sympathectomy produced a significant increase in ERP $(5.5 \pm 5.9 \mathrm{msec}, p<0.05)$, and a decrease in both arterial pressure and heart rate $(-26.3 \pm 26.2 \mathrm{mmHg}, p<0.05 ;-12.8 \pm 7.6$ beats/minute. $p<$ 0.05) (Table 1). The effect of the sympathectomy on $\triangle \mathrm{ERP}$ and $\triangle \mathrm{MAP}$ in response to coronary occlusion were summarized in Fig. 3. After cardiac sympathectomy, the mean change in ERP in the nonischemic area was virtually zero. However, there was a variability in the individual response. Thus, 4 of 7 cats showed a small decrease in ERP, whereas the original decrease in ERP was converted to an increase in the other 3 animals. The fall in MAP in response to coronary occlusion was apparently enhanced after sympathectomy. The maximal mean fall in MAP was $11.2 \pm 6.2 \mathrm{mmHg}$ at $60 \mathrm{sec}$ after coronary occlusion, which was significantly greater than that with the control occlusion $(3.3 \pm 7.0 \mathrm{mmHg})$.

\section{Effects of sinoaortic denervation on ERP responses to coronary occlusion}

Sinoaortic denervation performed in 8 cats produced a small, insignificant decrease in the ERP and a significant rise in arterial pressure (Table 1). Figure 4 summarizes the change in the ERP and MAP in response to coronary occlusion before and after denervation. The ERP response to coronary occlusion was significantly reduced but not abolished by the procedure. The maximal change was obtained at $90 \mathrm{sec}$ after occlusion; corresponding values before and after sinoaortic denervation were $-2.1 \pm 1.0 \mathrm{msec}$ and $-0.6 \pm 0.7 \mathrm{msec}$, respectively $(p<0.05)$. The arterial pressure change in response to coronary occlusion was significantly enhanced after sinoaortic denervation. Thus, after the denervation the decrease in MAP at $90 \mathrm{sec}$ after the coronary occlusion was $17.9 \pm 20.2 \mathrm{mmHg}$ as compared to a control fall of $6.4 \pm 9.4 \mathrm{mmHg}(p<0.05)$.
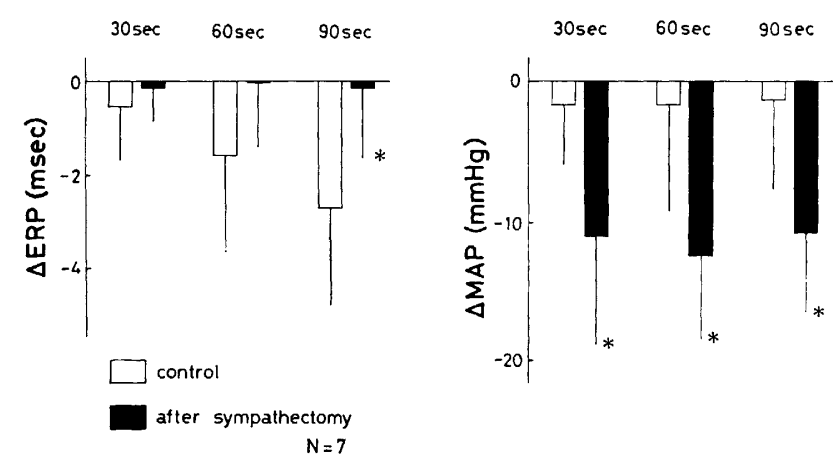

Fig. 3. Time course of changes in effective refractory period ( $\triangle \mathrm{ERP}, \mathrm{msec}$ ) of nonischemic area and mean arterial pressure ( $\triangle \mathrm{MAP}, \mathrm{mmHg}$ ) during $90 \mathrm{sec}$ of anterior descending coronary occlusion before (open bars) and after (solid bars) bilateral cardiac sympathectomy in 7 cats. Data are shown for each consecutive 30-sec period of occlusion. * Significantly different $(p<0.05)$ as compared to pre-sympathectomy values. 

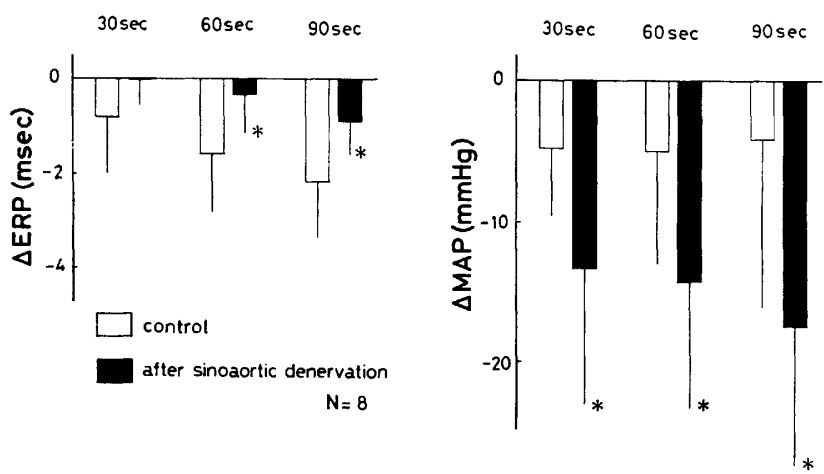

Fig. 4. Time course of changes in effective refractory period ( $\triangle \mathrm{ERP}, \mathrm{msec})$ of nonischemic area and mean arterial pressure $(\triangle \mathrm{MAP}, \mathrm{mmHg})$ during $90 \mathrm{sec}$ of anterior descending coronary occlusion before (open bars) and after (solid bars) sinoaortic denervation in 8 cats. Data are shown for each consecutive $30-\mathrm{sec}$ period of occlusion. * Significant differences $(p<0.05)$ between means for pre- $v s$. post-sinoaortic denervation.

\section{Effects of hypotension on ERP in denervated cats}

To determine whether the decrease in arterial pressue due to coronary occlusion directly affected ERP in the absence of autonomic nerve activity to the heart the effects of hemorrhagic hypotension on ERP were examined in 5 denervated cats. After all selective denervations (vagotomy, cardiac sympathectomy, and sinoaortic denervation), a sufficient amount of blood was removed from the femoral vein to decrease arterial pressure to the same extent as with coronary occlusion. After the hemorrhage, ERP was not changed significantly $(-0.4 \pm 0.9 \mathrm{msec})$, confirming the previously reported results (BLAIR et al., 1980).

\section{DISCUSSION}

The present study clearly demonstrates that acute coronary occlusion in the cat causes a small but significant decrease in ERP of the nonischemic ventricular myocardium. The degree of maximal ERP shortening, however, remained within the range of a few milliseconds, although it appeared to be increasing time-dependent. Since coronary occlusion of more than $90 \mathrm{sec}$ was not performed, possible changes in ERP in the nonischemic area which might have occurred with more prolonged myocardial ischemia were not known. The relatively short period of coronary occlusion was chosen because of the following two reasons. First, with a longer period of the occlusion, a greater variability in the ERP change was observed as well as an increased incidence of serious ventricular arrhythmias which hindered an accurate measurement of ERP. The second reason was that, in view of the previous studies (Felder and THAMES, 1979; IWAMURA and BishoP, 1980; THORÉN, 1976; WEAVER et al., 1981), $90 \mathrm{sec}$ was considered sufficiently long for the development of reflex alteration of ventricular refractoriness, and a much longer 
period of occlusion might allow mechanisms other than autonomic reflexes to take place.

The present results contrast with those of previous experimental studies on ERP changes in nonischemic area. LeviTes et al. (1975) demonstrated that the refractory period of nonischemic zones in the dog remained essentially unchanged after coronary occlusion. Similar results were obtained by others (NATTEL et al., 1981) in anesthetized dogs. The discrepancy may well be accounted for by the difference in experimental conditions. Since a major purpose of the present study was to detect reflex changes occurring early after the initiation of coronary occlusion, we adopted a relatively short period of coronary occlusion and ERP was determined with the accuracy of $1 \mathrm{msec}$ to detect subtle changes in nonischemic ventricular refractoriness. In previous studies, however, ERP of nonischemic area was obtained 15 to $30 \mathrm{~min}$ after coronary occlusion and determined with the accuracy of $5 \mathrm{msec}$. It is possible that the initial activation of a reflex would then be modified by other reflex mechanisms with a longer period of observation. Also, in addition to the possible species difference, potential difference in background autonomic tone due to the different anesthetic used might complicate the comparison of these results.

In the present study, cardiac sympathectomy almost abolished the change in ERP in response to coronary occlusion. This indicates that the ERP changes were reflex in origin and mediated mainly through cardiac sympathetic nerves. An increase in efferent sympathetic activity has been reported to shorten ERP of ventricular myocardium, whereas an increase in efferent vagal activity exerts opposite effects. Thus, the shortening of ERP in response to coronary occlusion may well be accounted for if efferent sympathetic discharge to the heart was increased. Coronary occlusion has been reported to produce increases in both sympathetic afferent and efferent activities (BROWN, 1967; FELDER and Thames, 1979; Gillis, 1971; LATHers et al., 1978; MALliani et al., 1969; UCHIDA and MURAO, 1974; WEAVER et al., 1981). In spinal cats, MALliANi et al. (1969) reported an increase in efferent sympathetic output to the heart during coronary occlusion and proposed a cardiocardiac sympathetic reflex. A more recent study by FELDER et al. (1981) demonstrated that increases in sympathetic outflow to the heart during coronary occlusion depended primarily on a decrease in arterial baroreceptor activity. In the present experiments, the reflex change in ERP was associated with hypotension and significantly blunted after sinoaortic denervation, suggesting that most part of the shortening in ERP was mediated by a decreased baroreceptor inhibition on sympathetic activities which developed secondary to hypotension during myocardial ischemia. These results are in agreement with those of MARTINS (1981) in which deactivation of carotid baroreflex by hypotension was shown to shorten the ventricular refractory period in anesthetized dogs. It is unlikely that the present change in ERP was directly affected by hypotension, since in the absence of reflex arcs, hypotension produced only insignificant changes in ERP. 
However, since sinoaortic denervation did not totally abolish the reflex change in ERP, there appears to be a possibility that a part of reflex changes may be mediated by cardiocardiac sympathetic reflex, although the excitatory sympathetic reflex has been demonstrated mainly in cord sectioned animals.

In addition, the results with vagotomy support the possibility of the coexistence of the vagal reflex. After vagotomy, the shortening in ERP in response to coronary occlusion was significantly augmented, indicating that the vagal inhibitory influence, either reflexly activated or tonically active, has limited the increases in efferent sympathetic activity. The lesser decrease in MAP during coronary occlusion after vagotomy would also suggest vagal involvement in the hypotensive reflex.

In summary, transient coronary artery occlusion produces a decrease in ventricular ERP of the nonischemic area mostly through an increased cardiac sympathetic outflow mediated by a reduced baroreceptor activity due to ischemia-induced hypotension. In addition, the net reflex change caused by coronary occlusion appeared to be limited by the simultaneously evoked vagal reflex and probable central integration of these neural inputs (CHEN, 1979; FeldER and THAMES, 1981; SHIMIzU and BishOP, 1980).

\section{REFERENCES}

Blair, W. B., Shimizu, T., and Bishop, V. S. (1980) The role of vagal afferents in the reflex control of the left ventricular refractory period in the cat. Circ. Res., 46: 378-386.

BrooKs, W. W., VerRIER, R. L., and Lown, B. (1978) Influence of vagal tone on stellectomyinduced changes in ventricular electrical stability. Am. J. Physiol., 234: H503-H507.

Brown, A. M. (1967) Excitation of afferent cardiac sympathetic nerve fibers during myocardial ischemia. J. Physiol. (Lond.), 190: 35-53.

CHEN, H. I. (1979) Interaction between the baroreceptor and Bezold-Jarisch reflexes. Am. J. Physiol., 237: H655-H661.

Felder, R. B. and Thames, M. D. (1979) Interaction between cardiac receptors and sinoaortic baroreceptors in the control of efferent cardiac sympathetic nerve activity during myocardial ischemia in dogs. Circ. Res., 45: 728-736.

Felder, R. B. and Thames, M. D. (1981) The cardiocardiac sympathetic reflex during coronary occlusion in anesthetized dogs. Circ. Res., 48: 685-692.

GILLIS, R. A. (1971) Role of the nervous system in the arrhythmias produced by coronary occlusion in the cat. Am. Heart J., 81: 677-684.

IWAMURA, N. and BISHOP, V. S. (1980) Afferent pathways of reflex hypotension and bradycardia during coronary occlusion. Am. J. Physiol., 239: H172-H180.

Kralios, F. and Millar, C. K. (1981) Sympathetic neural effects on regional atrial recovery properties and cardiac rhythm. Am. J. Physiol., 240: H590-H596.

Lathers, C. M., Kelliher, G. J., Roberts, J., and Beasley, A. B. (1978) Nonuniform cardiac sympathetic nerve discharge. Mechanism for coronary occlusion and digitalis-induced arrhythmias. Circulation, 57: 1058-1065.

Levites, R., Banka, V. S., and Helfant, R. H. (1975) Electrophysiologic effects of coronary occlusion and reperfusion. Observations of dispersion of refractoriness and ventricular automaticity. Circulation, 52: 760-765.

Vol. 33, No. 5, 1983 
Malliani, A., Schwartz, P. J., and Zanchetti, A. (1969) A sympathetic reflex elicited by experimental coronary occlusion. Am. J. Physiol., 217: 703-709.

MANCIA, G. J., SHEPHERD, T., and Donald, D. E. (1976) Interplay among carotid sinus, cardiopulmonary, and carotid body reflexes in dogs. Am. J. Physiol., 230: 19-24.

MARTINS, J. B. (1981) Baroreflex control of ventricular repolarization and refractoriness in the dog. Circulation (Suppl. IV), $64: 327$.

MARTINS, J. B. and ZIPES, D. P. (1980) Effects of sympathetic and vagal nerves on recovery properties of the endocardium and epicardium of the canine left ventricle. Circ. Res., 46: 100110.

Nattel, S., Euler, D. E., Spear, J. E., and Moore, E. N. (1981) Autonomic control of ventricular refractoriness. Am. J. Physiol., 241 : H878-H882.

Schwartz, P. J., Verrier, R. L., and Lown, B. (1977) Effect of stellectomy and vagotomy on ventricular refractoriness in dogs. Circ. Res., 40: 536-540.

ShimzU, T. and Bishop, V. S. (1980) Role of carotid sinus and cardiopulmonary reflexes on left ventricular $\mathrm{d} P / \mathrm{d} t$ in cats. Am. J. Physiol., 238: H93-H97.

Shimizu, T., Peterson, D. F., and Bishop, V. S. (1978) Reflex circulatory changes due to the afferent stimulation of cat pericoronary nerve. Am. J. Physiol., 235: H759-H766.

THORÉN, P. N. (1976) Activation of left ventricular receptors with nonmedullated vagal afferent fibers during occlusion of a coronary artery in the cat. Am. J. Cardiol., 37: 1046-1051.

UCHIDA, Y. and MuRAo, S. (1974) Excitation of afferent cardiac sympathetic nerve fibers during coronary occlusion. Am. J. Physiol., 226: 1094-1099.

Weaver, L. C., Danos, L. M., Oehl, R. S., and MeckleR, R. L. (1981) Contrasting reflex influences of cardiac afferent nerves during coronary occlusion. Am. J. Physiol., 240: H620H629. 